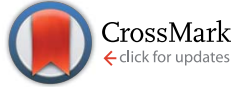

Cite this: J. Mater. Chem. C, 2014, 2 , 8789

Received 10th July 2014

Accepted 25th August 2014

DOI: $10.1039 / c 4 t c 01500 b$

www.rsc.org/MaterialsC

\section{The effect of thiadiazole out-backbone displacement in indacenodithiophene semiconductor polymers $\dagger$}

\author{
Miquel Planells, ${ }^{* a}$ Mark Nikolka, ${ }^{b}$ Michael Hurhangee, ${ }^{a}$ Pabitra S. Tuladhar, ${ }^{a}$ \\ Andrew J. P. White, ${ }^{a}$ James R. Durrant, ${ }^{a}$ Henning Sirringhaus ${ }^{b}$ and lain McCulloch ${ }^{a}$
}

We describe the synthesis and characterisation of two new polymers consisting of an electron-rich backbone containing indacenodithiophene (IDT) and dithiophene (DT) with the electron-poor units benzothiadiazole (BT) and benzopyrazolothiadiazole (BPT) fused on top of DT. The effect of this substitution has been studied and discussed by optical, electrochemical and computational means. Despite having very similar molecular distribution as well as thermal and electrochemical properties, the addition of the stronger electron-withdrawing BPT unit leads to a substantial change on the absorption properties by promoting the intramolecular charge transfer (ICT) band alongside the $\pi-\pi^{*}$. Furthermore, we also report organic field effect transistor and solar cells device results, giving hole mobilities of 0.07 $\mathrm{cm}^{2} \mathrm{~V}^{-1} \mathrm{~s}^{-1}$ with low threshold voltage $(<10 \mathrm{~V})$ and power conversion efficiencies of up to $2.2 \%$.

\section{Introduction}

Semiconductor polymers have attracted much attention from scientific community due to their potential low cost production of organic electronic devices, roll-to-roll solution processing as well as their use in lightweight and flexible applications. ${ }^{1-3}$

The indacenodithiophene (IDT) unit has been successfully employed as an electron rich, conformationally rigid repeat unit in a range of high performing polymers for both transistor and solar cell applications. ${ }^{4}$ There are several features at the molecular level that make this unit attractive. With the aromatic units fixed co-planar due to the bridging groups, a low energetic disorder close packed intramolecular conformation is feasible. It is believed that IDT-BT copolymers can tolerate significant intermolecular disorder, and still maintain good charge transport, in part due to the excellent backbone rigidity, which allows charges to be transported along the polymer chain and $\pi$ stacking (usually present in crystalline domains) is only occasionally required. ${ }^{5}$

The electron poor benzothiadiazole (BT) unit has been used extensively as a co-monomer in many light absorbing donoracceptor polymers in bulk heterojunction OPV devices, as it promotes efficient molecular orbital hybridisation, which

${ }^{a}$ Department of Chemistry and Centre for Plastic Electronics, Imperial College London, London SW7 2AZ, UK. E-mail: m.planells@imperial.ac.uk

${ }^{b}$ Cavendish Laboratory, University of Cambridge, Cambridge CB3 OHE, UK

$\dagger$ Electronic supplementary information (ESI) available: DSC, CV, ${ }^{1} \mathrm{H}-\mathrm{NMR}$ and PL experiments of $\mathrm{C}_{16}$ IDT based polymers. UV-Visible absorption of 3 and TD-DFT tables. CCDC 992593. For ESI and crystallographic data in CIF or other electronic format: see DOI: $10.1039 / \mathrm{c} 4 \mathrm{tc} 01500 \mathrm{~b}$ allows fine band gap tuning. ${ }^{2}$ In addition, the off-axis dipole moment is believed to have a contribution on the charge transport properties of IDT-BT polymers as the sterically free BT units from adjacent polymer backbones can adopt an antiparallel dipole alignment to each other, thus facilitating close intermolecular contacts. ${ }^{6}$

Therefore, fused systems, which reduce the conformational disorder, containing BT units, which enhance the off axis dipole moment, seem to be promising molecular design guidelines to obtain high charge carrier mobility polymers for both OFET and OPV applications.

In this paper, we describe the synthesis and characterisation of two monomers prepared by fusing dithiophene units with both a new benzopyrazolothiadiazole BPT unit and its BT analogue (Fig. 1). ${ }^{7}$ We co-polymerize both these monomers with the $\mathrm{C}_{16}$ IDT monomer and study the optical, electrochemical and thermal properties of the polymers as well as their performance in OFET and OPV devices.

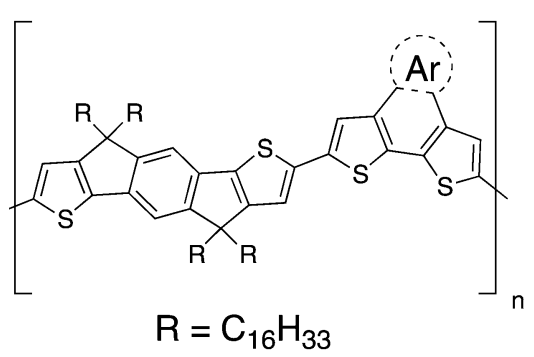

$$
\mathrm{Ar}=\mathrm{C}_{16} \text { IDT-fDTBT }
$$

Fig. 1 Molecular structures of $C_{16}$ IDT based polymers used in this study. 


\section{Experimental section}

\section{Synthetic procedure}

Materials. All starting materials were of reagent grade and purchased from commercial suppliers unless otherwise specified. 1 has been synthesised following a modified reported procedure. ${ }^{8}$ Anhydrous solvents were bought from Acros Organics under a molecular sieve (less than $0.01 \% \mathrm{H}_{2} \mathrm{O}$ ).

Synthesis of $[1,2,5]$ thiadiazolo[3,4-b]dithieno[3,2-f:2', $\left.3^{\prime}-h\right] q u i-$ noxaline (2). 1 (110 mg, $0.5 \mathrm{mmol})$ and 1,2,5-thiadiazole-3,4diamine (64 mg, $0.55 \mathrm{mmol}$ ) were added to a microwave vial. 10 $\mathrm{mL}$ of previously degassed acetic acid was added via syringe and the mixture was stirred overnight at reflux. After cooling down, the product was obtained by filtration and washed with $10 \mathrm{~mL}$ of $\mathrm{AcOH}, \mathrm{MeOH}$ and $\mathrm{CHCl}_{3}$, giving a black solid $(73 \mathrm{mg}, 50 \%$ yield). ${ }^{1} \mathrm{H}$ NMR (400 MHz, TCE- $\left.d_{2}\right) \delta_{\mathrm{H}}: 8.45(\mathrm{~d}, J=5.5 \mathrm{~Hz}, 2 \mathrm{H}$ ); $7.66(\mathrm{~d}, J=5.3 \mathrm{~Hz}, 2 \mathrm{H}) .{ }^{13} \mathrm{C}$ NMR $\left(100 \mathrm{MHz}, \mathrm{TCE}-d_{2}\right) \delta_{\mathrm{C}}: 152.4$; $143.7 ; 138.6 ; 134.1 ; 125.8 ; 125.7$.

Synthesis of 2,5-dibromo-[1,2,5]thiadiazolo[3,4-b]dithieno[3,2$f: 2^{\prime}, 3^{\prime}$-h]quinoxaline (3). $2(73 \mathrm{mg}, 0.25 \mathrm{mmol})$ was added to a round bottom flask with $75 \mathrm{~mL}$ of $\mathrm{CHCl}_{3}$. Bromine $(38 \mu \mathrm{L}, 0.75$ $\mathrm{mmol}$ ) was added and the mixture was stirred at reflux overnight. After cooling down, the product was obtained by filtration and washed with copious amounts of $\mathrm{CHCl}_{3}$ and $\mathrm{CH}_{2} \mathrm{Cl}_{2}$. ${ }^{1} \mathrm{H}$ NMR (400 MHz, TCE- $d_{2}$ @ $120{ }^{\circ} \mathrm{C}$ ) $\delta_{\mathrm{H}}: 8.50$ (s, 2H). ${ }^{13} \mathrm{C}$ NMR $\left(100 \mathrm{MHz}, \mathrm{TCE}-d_{2}\right.$ @ $\left.120{ }^{\circ} \mathrm{C}\right) \delta_{\mathrm{C}}: 152.8 ; 142.1 ; 134.6 ; 128.4 ; 120.2$; 114.2. MS EI $(\mathrm{m} / \mathrm{z}):[\mathrm{M}]^{+}$calcd for $\mathrm{C}_{12} \mathrm{H}_{2} \mathrm{~N}_{4} \mathrm{~S}_{3} \mathrm{Br}_{2}$ : 455.7808; found: 455.7810 .

Synthesis of benzo[1,2-b:6,5- $\left.b^{\prime}\right]$ dithiophene-4,5-diamine (4). 1 (364 mg, $1 \mathrm{mmol}$ ) and $\mathrm{NH}_{2} \mathrm{OH} \cdot \mathrm{HCl}(173 \mathrm{mg}, 2.5 \mathrm{mmol})$ were added to a round bottom flask with $10 \mathrm{~mL}$ of EtOH. The mixture was heated at reflux overnight. Then, the reaction mixture was allowed to cool down to room temperature and $\mathrm{Pd} / \mathrm{C} 10 \%$ (20 $\mathrm{mg}$ ) was added. The reaction mixture was warmed up to $60{ }^{\circ} \mathrm{C}$ and $\mathrm{N}_{2} \mathrm{H}_{4} \cdot \mathrm{H}_{2} \mathrm{O}(1.5 \mathrm{~mL})$ in $2.5 \mathrm{~mL}$ EtOH was added via the addition funnel from the top of the condenser. After that, the reaction mixture was heated at reflux overnight. After cooling to room temperature, the crude product was plugged in EtOAc to remove $\mathrm{Pd} / \mathrm{C}$ and further purified by column chromatography $\left(\mathrm{SiO}_{2}, \mathrm{CH}_{2} \mathrm{Cl}_{2}\right.$ up to $\mathrm{CH}_{2} \mathrm{Cl}_{2}$-EtOAc $\left.1: 1\right)$ to afford the product as a yellow solid (190 $\mathrm{mg}, 86 \%$ yield). ${ }^{1} \mathrm{H}$ NMR $\left(400 \mathrm{MHz}, \mathrm{DMSO}-d_{6}\right) \delta_{\mathrm{H}}: 7.60(\mathrm{~d}, J=$ $5.4 \mathrm{~Hz}, 2 \mathrm{H}) ; 7.45(\mathrm{~d}, J=5.4 \mathrm{~Hz}, 2 \mathrm{H}) .{ }^{13} \mathrm{C} \mathrm{NMR}\left(100 \mathrm{MHz}, \mathrm{CDCl}_{3}\right)$ $\delta_{\mathrm{C}}: 129.3 ; 124.7 ; 122.4 ; 122.3 ; 121.8$.

Synthesis of dithieno $\left[3^{\prime}, 2^{\prime}: 3,4 ; 2^{\prime}, 3^{\prime}: 5,6\right]$ benzo[1,2-c][1,2,5]thiadiazole (5). $\mathrm{S}_{2} \mathrm{Cl}_{2}(256 \mu \mathrm{L}, 3.2 \mathrm{mmol})$ was added to a round bottom flask with $1.6 \mathrm{~mL}$ of DMF and stirred at $0{ }^{\circ} \mathrm{C}$ under Ar. Then, a previously made solution of $4(176 \mathrm{mg}, 0.80 \mathrm{mmol})$ in $1.6 \mathrm{~mL}$ of DMF was added dropwise. After addition, the mixture was allowed to warm at room temperature and stirred for further 2 hours. Ice-water was added to quench the reaction and extraction was carried out using $\mathrm{CH}_{2} \mathrm{Cl}_{2}$. The organic layer was washed with brine, dried over $\mathrm{MgSO}_{4}$, filtered and the solvent was removed. The crude was further purified by column chromatography $\left(\mathrm{SiO}_{2}\right.$, hexane- $\left.\mathrm{CH}_{2} \mathrm{Cl}_{2} 2: 1\right)$ to afford the product as a yellow solid (110 mg, 55\% yield). ${ }^{1} \mathrm{H}$ NMR (400 $\mathrm{MHz}, \mathrm{CDCl}_{3}$ )
$\delta_{\mathrm{H}}: 8.03(\mathrm{~d}, J=5.2 \mathrm{~Hz}, 2 \mathrm{H}) ; 7.54(\mathrm{~d}, J=5.2 \mathrm{~Hz}, 2 \mathrm{H}) .{ }^{13} \mathrm{C} \mathrm{NMR}$ $\left(100 \mathrm{MHz}, \mathrm{CDCl}_{3}\right) \delta_{\mathrm{C}}: 150.8 ; 135.8 ; 129.1 ; 125.5 ; 124.4$.

Synthesis of 5,8-dibromodithieno $\left[3^{\prime}, 2^{\prime}: 3,4 ; 2^{\prime}, 3^{\prime}: 5,6\right]$ benzo[1,2-c]$[1,2,5]$ thiadiazole (6). $5(110 \mathrm{mg}, 0.45 \mathrm{mmol})$ was added to a round bottom flask equipped with a reflux condenser and 36 $\mathrm{mL}$ of $\mathrm{CHCl}_{3}$. Bromine (0.05 mL, $0.99 \mathrm{mmol}$ ) was added dropwise and the mixture was stirred at reflux for 6 hours, during which a yellow precipitate appeared. After that, the temperature was switched off and the mixture was stirred overnight. The resulting solid was filtered off and washed with copious amounts of $\mathrm{CHCl}_{3}$ and $\mathrm{CH}_{2} \mathrm{Cl}_{2}$, giving a bright yellow solid (105 $\mathrm{mg}, 63 \%$ yield). ${ }^{1} \mathrm{H}$ NMR $\left(400 \mathrm{MHz}\right.$, TCE- $d_{2}$ @ $\left.120{ }^{\circ} \mathrm{C}\right) \delta_{\mathrm{H}}: 8.09(\mathrm{~s}$, 2H). ${ }^{13} \mathrm{C}$ NMR (100 MHz, TCE- $d_{2}$ @ $120{ }^{\circ} \mathrm{C}$ ) $\delta_{\mathrm{C}}: 149.1 ; 129.1$; $126.9 ; 120.2 ; 114.1$.

General polymer synthesis and purification. An oven-dried microwave vial was charged with distannylated $\mathrm{C}_{16}$ IDT $(149 \mathrm{mg}$, $0.10 \mathrm{mmol}$ ), and 1 eq. of 3 (46 mg, $0.10 \mathrm{mmol}$ ) or 6 (41 mg, 0.10 mmol) together with $\mathrm{Pd}\left(\mathrm{PPh}_{3}\right)_{4}(4.7 \mathrm{mg}, 4 \mu \mathrm{mol}, 4 \mathrm{~mol} \%)$. The vial was sealed, and dry $o$-xylene $(1 \mathrm{~mL})$ was added. The reaction mixture was degassed with argon for $30 \mathrm{~min}$ before being placed into the microwave reactor and subjected to the following heating conditions: $120^{\circ} \mathrm{C}$ for $2 \mathrm{~min}, 140{ }^{\circ} \mathrm{C}$ for $2 \mathrm{~min}, 160^{\circ} \mathrm{C}$ for $2 \mathrm{~min}$, and $180^{\circ} \mathrm{C}$ for $40 \mathrm{~min}$. Once the reaction mixture had cooled, polymer crude solution was precipitated by adding it dropwise into an acidic $\mathrm{MeOH}$ solution (containing $1 \% \mathrm{HCl}$ ) and stirred for 1-3 h until fine powder was obtained. The precipitate was filtered off into a cellulose thimble and soxhlet extraction in acetone (16 h) and hexane (16 h) was carried out. The remaining solid was soxhlet extracted in $\mathrm{CHCl}_{3}$ for 2 hours in order to extract the polymer. The organic layer was washed with sodium diethyldithiocarbamate aqueous solution three times, dried over $\mathrm{Na}_{2} \mathrm{SO}_{4}$, filtered off and solvent was removed. Preparative GPC in chlorobenzene at $80{ }^{\circ} \mathrm{C}$ was carried out and the polymer was fractionated by molecular weight (MW). Low MW fractions were discarded and high MW fractions were combined, solvent removed and re-precipitated by adding into a stirring $\mathrm{MeOH}$ solution to afford $\mathrm{C}_{16} \mathrm{IDT}-\mathrm{fDTBT}$ (71 $\mathrm{mg}, 50 \%$ ) and $\mathrm{C}_{16}$ IDT-fDTBPT ( $66 \mathrm{mg}, 45 \%$ ) as dark solids. The collected polymer was dried under high vacuum for 24 hours before characterisation.

\section{Methods}

Chemical characterisation. ${ }^{1} \mathrm{H}$ and ${ }^{13} \mathrm{C}$ NMR spectra were recorded on a Bruker Advance 400 spectrometer $(400 \mathrm{MHz}$ for ${ }^{1} \mathrm{H}$ and $100 \mathrm{MHz}$ for ${ }^{13} \mathrm{C}$ ). The deuterated solvents are indicated; chemical shifts, $\delta$, are given in ppm, referenced to TMS, standardized by the solvent residual signal $\left({ }^{1} \mathrm{H},{ }^{13} \mathrm{C}\right)$. Numberaverage $\left(M_{\mathrm{n}}\right)$ and weight-average $\left(M_{\mathrm{w}}\right)$ molecular weights were determined with an Agilent Technologies 1200 series GPC in chlorobenzene at $80{ }^{\circ} \mathrm{C}$, using two PL mixed B columns in series, and calibrated against narrow polydispersity polystyrene standards. DSC experiments were carried out with a TA Instrument DSC Q20 and TGA plots were obtained with a PerkinElmer Pyris 1 TGA.

Electrochemical characterisation. All cyclic voltammetry measurements were carried out in dry acetonitrile using a $0.1 \mathrm{M}$ $[\mathrm{TBA}]\left[\mathrm{PF}_{6}\right]$ electrolyte in a three-electrode system, with each solution being purged with $\mathrm{N}_{2}$ prior to measurement. The 
working electrode was ITO treated glass, the reference electrode was $\mathrm{Ag} / \mathrm{AgCl}$ and the counter electrode was a Pt rod. All cyclic voltammetry (CV) measurements were carried out at room temperature using an AUTOLAB PGSTAT101 potentiostat at a 50 $\mathrm{mV} \mathrm{s}^{-1}$ scan rate and referenced to ferrocene.

Optical characterisation. Solution and solid state UV-Visible absorption spectra were recorded using a UV-1601 Shimadzu UV-Vis spectrophotometer. Photoluminescence (PL) spectra were recorded with a Fluoromax-3 fluorimeter. All samples were measured in either a $1 \mathrm{~cm}$ cell at room temperature or a spincoated film.

Computational details. The molecular structures were optimized in a vacuum without any symmetry constraints. All calculations were carried out using the Gaussian 09 program $^{9}$ with the Becke three parameter hybrid exchange and Lee YangParr correlation functional (B3LYP) level of theory. All atoms were described by the $6-31 \mathrm{G}(\mathrm{d})$ basis set. All structures were input and processed using Avogadro software package. ${ }^{10}$ Timedependent calculations (TD-DFT) were performed using the same level of theory B3LYP/6-31G(d). ${ }^{11,12}$ The 10 lowest singlet electronic transitions were calculated and processed using GaussSum software package. ${ }^{13}$

OFET fabrication. For the fabrication of bottom-contact topgate OFETs, Ti/Au $(10 \mathrm{~nm} / 30 \mathrm{~nm})$ bottom electrodes were patterned by photolithography on clean glass substrates. The patterning was done using a double layer lift-off process in $\mathrm{N}$ methyl-2-pyrrolidone (NMP). Polymers were deposited by spin coating on solvent cleaned electrodes (Sonicated in Acetone and IPA), followed by an annealing step at $100{ }^{\circ} \mathrm{C}$ for $1 \mathrm{~h}$. Subsequently, a $500 \mathrm{~nm}$ layer of Cytop (Asahi Glass) was spin coated and devices were finished off by evaporating a $20 \mathrm{~nm}$ thick gold top gate through a shadow mask. Transistor transfer characteristics were measured with an Agilent 4155B Semiconductor Parameter Analyser with all charge carrier mobility values being determined from the square root of the saturation transfer curve. To guarantee reproducibility, all fabrication steps were performed in an $\mathrm{N}_{2}$ glove box.

OPV fabrication. ITO-coated glass substrates were cleaned with acetone and isopropyl alcohol followed by nitrogen blowdrying and oxygen plasma treatment. A $30 \mathrm{~nm}$ layer of PEDOT:PSS (AI4083, Clevios) was spin-coated onto the plasmatreated ITO substrate and annealed at $150{ }^{\circ} \mathrm{C}$ for $15 \mathrm{~min}$. An active layer consisting of $1: 3.5$ blend of the polymer $(12 \mathrm{mg}$ $\mathrm{mL}^{-1}$ ) and $\mathrm{PC}_{71} \mathrm{BM}$ (Solenne, BV) dissolved in $o$-dichlorobenzene (o-DCB) was spin-coated on the PEDOT:PSS layer in air and then the $\mathrm{Ca}(20 \mathrm{~nm}) / \mathrm{Al}(100 \mathrm{~nm})$ cathode was finally deposited by thermal evaporation under high vacuum $\left(10^{-6} \mathrm{mbar}\right)$ through a shadow mask. The pixel size, defined by the spatial overlap of the ITO anode and the $\mathrm{Ca} / \mathrm{Al}$ cathode, was $0.045 \mathrm{~cm}^{2}$. The device characteristics were measured using a xenon lamp at AM1.5 solar illumination (Oriel Instruments).

\section{Results and discussion}

\section{Synthesis and chemical properties}

The synthesis of monomers and $\mathrm{C}_{16} \mathrm{IDT}$ based polymers is shown in Scheme 1. The key intermediate diketone $\mathbf{1}$ was

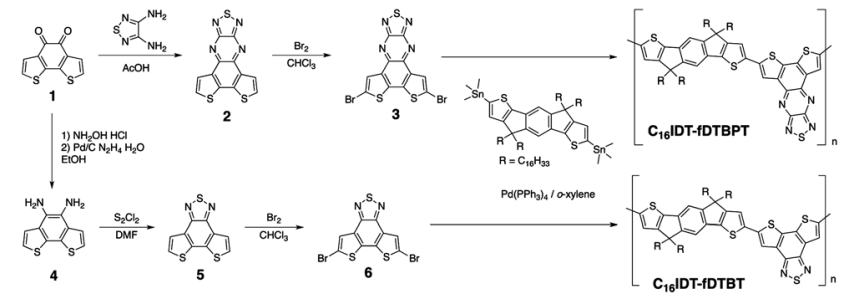

Scheme 1 Synthetic pathway to $C_{16}$ IDT based polymers.

obtained using a modified reported literature procedure. ${ }^{8}$ Condensation of 1 with diaminothiadiazole ${ }^{14}$ in the presence of acetic acid gave $\mathbf{2}$ in good yields. Diketone 1 was successfully reduced to yield diamine 4 and fused dithienobenzothiadiazole 5 was obtained after ring closure. ${ }^{7}$ Dibrominated co-monomers 3 and 6 were successfully achieved by refluxing with bromine. ${ }^{7}$ It is worth mentioning that both co-monomers possessed low solubility.

Although the packing between monomeric units might not accurately describe the polymer intermolecular interactions between benzothiadiazole moieties, it could definitely provide valuable information. Thus, single crystals suitable for XRD analysis of the fused DTBPT unit 2 were obtained by slow evaporation in chloroform. $\$$ The crystal structure of 2 (Fig. 2a) shows the molecule to be almost completely flat, all of the nonhydrogen atoms being coplanar to within $c a .0 .05 \AA$. Glide related molecules pack in a canted fashion along the crystallographic $a$-axis direction such that the major molecular axis (defined as the vector between the centroids of rings $\mathbf{A}$ and $\mathbf{C}$ ) of adjacent molecules is inclined by $c a .135^{\circ}$ (see Fig. 2b). The closest approaches are between ring $\mathbf{B}$ in one molecule and ring $\mathbf{C}$ in the "above" counterpart (centroid $\cdots$ centroid and mean interplanar distances of $c a .3 .55$ and $3.40 \AA$, rings inclined by $c a$. $1^{\circ}$ ), and between ring $\mathbf{B}$ in one molecule and ring $\mathbf{E}$ in the "below" counterpart (centroid $\cdots$ centroid and mean interplanar



Fig. 2 (a) Crystal structure of fused DTBPT unit 2, (b) its packing on the $\pi-\pi$ stacking direction along the a-axis and (c) $\mathrm{S}-\mathrm{N}$ short contact interactions between adjacent thiadiazole units along the $c$-axis.

$\ddagger$ Crystal data for 2: $\mathrm{C}_{12} \mathrm{H}_{4} \mathrm{~N}_{4} \mathrm{~S}_{3}, M=300.37$, orthorhombic, Pna2 ${ }_{1}$ (no. 33), $a=$ 7.22656(17), $b=18.9016(4), c=8.35979(18) \AA, V=1141.89(4) \AA^{3}, Z=4, D_{\mathrm{c}}=$ $1.747 \mathrm{~g} \mathrm{~cm}^{-3}, \mu(\mathrm{Cu}-\mathrm{K} \alpha)=5.844 \mathrm{~mm}^{-1}, T=173 \mathrm{~K}$, dark red blocky needles, Agilent Xcalibur PX Ultra A diffractometer; 1453 independent measured reflections $\left(R_{\text {int }}=0.0209\right), F^{2}$ refinement, $R_{1}(\mathrm{obs})=0.0249, \mathrm{w} R_{2}(\mathrm{all})=0.0637$, 1404 independent observed absorption-corrected reflections $\left[\left|F_{\mathrm{o}}\right|>4 \sigma\left(\left|F_{\mathrm{o}}\right|\right)\right.$,

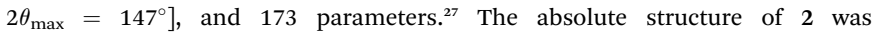
determined by a combination of $R$-factor tests $\left[R_{1}{ }^{+}=0.0249\right.$ and $\left.R_{1}{ }^{-}=0.0367\right]$ and by use of the Flack parameter $\left[x^{+}=0.05(2)\right.$ and $\left.x^{-}=0.94(2)\right]$. CCDC 992593. 
distances of $c a .3 .57$ and $3.37 \AA$, rings inclined by $c a .1^{\circ}$ ). This quasi head-to-tail packing motif is characteristic for nonsymmetrical donor-acceptor molecules, as their molecular dipole moments predispose to cancel each other. ${ }^{\mathbf{1 5 , 1 6}}$

More interestingly, adjacent screw-related molecules are linked by an $\mathrm{S} \cdots \mathrm{N}$ short contact of 3.302(3) A between $\mathrm{S}(1)$ in one molecule and $\mathrm{N}(2)$ in the next, forming a chain along the crystallographic $c$-axis direction (Fig. 2c). This short contact confirms that the intermolecular interactions between fDTBPT units are strong and achievable and they might potentially help inter-backbone polymer charge transport by attracting polymer chains together.

Both monomers were co-polymerised via microwave assisted Stille coupling with stannylated $\mathrm{C}_{16}$ IDT. ${ }^{17}$ Purification of the crude polymers was carried out by Soxhlet extraction with acetone, hexane and then with chloroform to extract the polymer product. Both polymers exhibited good solubility in common organic solvents despite the rigidity of the electronaccepting unit. Preparative GPC in chlorobenzene was also carried out in order to further purify and remove low molecular weight polymer fractions. ${ }^{18}$

Polymer molecular weights and polydispersity were determined by GPC analysis and referenced to polystyrene standards and are shown in Table 1. Although the PDIs are similar (1.5) for both polymers, lower molecular weights were obtained for the $\mathrm{C}_{16}$ IDT-fDTBPT polymer, presumably due to the lower solubility of co-monomer 6 .

Thermal stability, which is a very important factor in organic electronic devices, was evaluated by TGA carried out under a $\mathrm{N}_{2}$ atmosphere (Fig. 3). Both polymers showed high temperature decomposition temperatures ( $5 \%$ loss on weight), particularly over $400{ }^{\circ} \mathrm{C}$ (Table 1). Furthermore, DSC scans were performed showing no obvious transitions and therefore supporting the evidence that $\mathrm{C}_{16}$ IDT based polymers have an amorphous character (Fig. S1†). ${ }^{19}$

\section{Energy levels}

Most low band gap semiconducting co-polymers consist of alternating electron rich (e.g. IDT) and electron deficient (e.g. BT) units. ${ }^{4}$ In this case, the electron rich unit is delocalized along the whole polymer backbone while the electron poor unit is localised on one co-monomer (Fig. 4). This configuration is crucial to understand the electrochemical and optical properties and therefore the energy levels of both polymers. ${ }^{20}$

Table 1 Polymer chemical ${ }^{a}$ and thermal ${ }^{b}$ properties

\begin{tabular}{llllll}
\hline Polymer & $M_{\mathrm{n}} / \mathrm{g} \mathrm{mol}^{-1}$ & $M_{\mathrm{w}} / \mathrm{g} \mathrm{mol}^{-1}$ & PDI & $\mathrm{DP}_{n}{ }^{c}$ & $T_{\mathrm{d}} /{ }^{\circ} \mathrm{C}$ \\
\hline fDTBT & 29000 & 43000 & 1.52 & 20 & 427 \\
fDTBPT & 20000 & 29000 & 1.45 & 13 & 400
\end{tabular}

${ }^{a}$ Average molecular weight in number $\left(M_{\mathrm{n}}\right)$ and in weight $\left(M_{\mathrm{w}}\right)$ and weight-average polydispersity PDI $\left(M_{\mathrm{w}} / M_{\mathrm{n}}\right)$ as determined by GPC in chlorobenzene at $80{ }^{\circ} \mathrm{C}$ and calibrated on polystyrene standards. ${ }^{b}$ Decomposition temperature determined by TGA under $\mathrm{N}_{2}$ and based on $5 \%$ weight loss. ${ }^{c}$ The degree of polymerization $\left(\mathrm{DP}_{n}\right)$ is defined in this case as the number of repeating units.

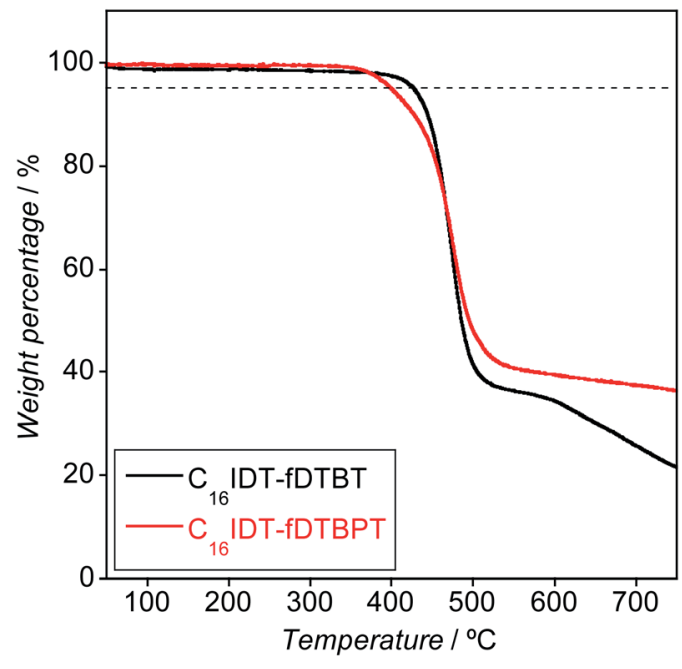

Fig. 3 Thermogravimetric analysis (TGA) of $\mathrm{C}_{16}$ IDT-fDTBT (black line) and $\mathrm{C}_{16} \mathrm{IDT}$-fDTBPT (red line) measured under $\mathrm{N}_{2}$ atmosphere. Dashed line indicates $5 \%$ mass loss.

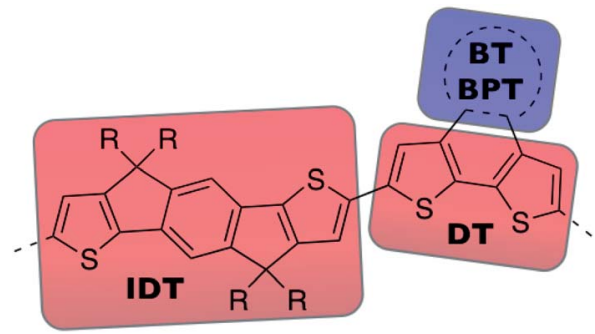

Fig. 4 Schematic representation of $C_{16}$ IDT based co-polymers used in this study, where red and blue colours indicate electron-rich and electron-poor units, respectively.

The HOMO energy levels were determined by cyclic voltammetry (CV) and compared to photoelectron spectroscopy in air (PESA), and they are shown in Table 2. Oxidation potentials of $+0.59 \mathrm{~V}$ and $+0.55 \mathrm{~V}$ for $\mathrm{C}_{16}$ IDT-fDTBT and $\mathrm{C}_{16}$ IDT-fDTBPT were obtained from the oxidation onset after calibrating externally with ferrocene $E_{1 / 2}$ (Fig. S2 $\dagger$ ). The oxidation potentials (V) were converted to $E_{\text {Hомо }}(\mathrm{eV})$ by following a procedure which employs an empirical linear translation equal to $E_{\text {номо }}$ $(\mathrm{eV})=-4.88-E_{\mathrm{Ox}}(\mathrm{V}) .{ }^{21}$ Not unexpectedly, the oxidation potential was very similar for both polymers. This is because the HOMO is predominantly located on the electron rich IDT and DT units (Fig. 4), common to both polymers and confirmed by DFT calculations (see below). $E_{\text {номо values are in good agree- }}$ ment with previous IDT based polymers. ${ }^{17,19}$ The LUMO energy levels were obtained by addition of the optical gaps (see below) to the HOMO and they differed substantially, being $\mathrm{C}_{16}$ IDTfDTBPT $0.6 \mathrm{eV}$ deeper than $\mathrm{C}_{16}$ IDT-fDTBT. This can be attributed to the stronger electron-withdrawing ability of the fDTBPT unit.

UV-Visible absorption profiles were acquired in both solution and solid state (Fig. 5). The main absorption bands in chloroform solution were located at $566 \mathrm{~nm}$ and $534 \mathrm{~nm}$ for 
Table 2 Solid state optical and electrochemical properties of $\mathrm{C}_{16}$ IDT based polymers

\begin{tabular}{|c|c|c|c|c|c|c|}
\hline Polymer & $\lambda_{\max } / \mathrm{nm}$ & $\lambda_{\text {onset }} / \mathrm{nm}$ & $E_{\text {gap }}{ }^{a} / \mathrm{eV}$ & $E_{\mathrm{Ox}}^{b} / \mathrm{V}$ & $E_{\text {номо }}^{c} / \mathrm{eV}$ & $E_{\mathrm{LUMO}}{ }^{d} / \mathrm{eV}$ \\
\hline fDTBT & 577 & 614 & 2.02 & +0.59 & $\begin{array}{l}-5.47 \\
(-5.46)\end{array}$ & -3.45 \\
\hline fDTBPT & 730 & 900 & 1.38 & +0.55 & $\begin{array}{l}-5.43 \\
(-5.42)\end{array}$ & -4.05 \\
\hline
\end{tabular}

${ }^{a}$ Optical gap from the onset of absorption spectrum. ${ }^{b} \mathrm{CV}$ measured from $0.1 \mathrm{M}[\mathrm{TBA}]\left[\mathrm{PF}_{6}\right]$ in $\mathrm{CH}_{3} \mathrm{CN}$ and referenced to ferrocene. ${ }^{c} E_{\text {HOMO }}(\mathrm{eV})=-4.88-E_{\mathrm{Ox}}(\mathrm{V})$. PESA results are shown in brackets. ${ }^{d} E_{\mathrm{LUMO}}=E_{\mathrm{HOMO}}+E_{\text {gap }}$.



Fig. 5 UV-Visible absorption of $C_{16}$ IDT-fDTBT (black line) and $\mathrm{C}_{16}$ IDT-fDTBPT (red line) measured at $0.02 \mathrm{mg} \mathrm{mL}^{-1}$ in chloroform (solid line) and in solid state (dashed line).

$\mathrm{C}_{16}$ IDT-fDTBT and -fDTBPT, respectively, with a well-defined vibronic structure. UV-Visible absorption in the solid-state was only $5 \mathrm{~nm}$ red-shifted compared to solution experiments, suggesting the absence of strong aggregation effects. Interestingly, the $\mathrm{C}_{16}$ IDT-fDTBPT polymer showed a red-shifted and broad band located at $760 \mathrm{~nm}$, with much lower intensity than the main absorption band.

The molecular (chemical) origin of those absorption bands was not straightforward to establish. Thus, in order to shed some light on the optical results, we performed hybrid DFT calculations at the B3LYP/6-31G(d) level of theory on a trimer system which was chosen as an approximation to our polymers. ${ }^{22}$ As shown in Fig. 6, the HOMO for both polymers is fully delocalized into the $\pi$ orbitals and therefore the electron-deficient unit BT or BPT have minimal influence on it. This justifies that both polymers have approximately the same HOMO energy level as shown previously on CV and PESA results. On the other hand, the LUMO is mainly $\pi^{*}$ based for the $\mathrm{C}_{16}$ IDT-fDTBT trimer, with little contribution from the extended BT unit and therefore the main electronic transition is $\pi-\pi^{*}$ based. However, for $\mathrm{C}_{16}$ IDT-fDTBPT, the LUMO has 3-fold degeneracy (as no symmetry is included on the calculation) and it is exclusively based on the electron-withdrawing BPT unit.


Fig. 6 Molecular orbital distribution of the $\mathrm{C}_{16}$ IDT-fDTBT trimer (left) and $\mathrm{C}_{16}$ IDT-fDTBPT (right) at the B3LYP/6-31G(d) level of theory (isodensity $=0.02$ ).

Hence, for $\mathrm{C}_{16}$ IDT-fDTBPT the first electronic transition is an intramolecular charge transfer (ICT) band from the thiophene bridged system (IDT-DT) to the electron-deficient BPT unit and it relates to the low-energy broad band observed in the UV-Visible spectrum (Fig. 5). Furthermore, the LUMO+1 is $\pi^{*}$ based and the second electronic transition (HOMO to LUMO+1) corresponds to the sharp and high-energy absorption peak observed in the experimental spectrum and has $\pi-\pi^{*}$ character. TD-DFT calculations confirm that both ICT and $\pi-\pi^{*}$ take place in $\mathrm{C}_{16}$ IDT-fDTBPT with higher oscillator strength for the $\pi-\pi *$ electronic transition (Fig. 7 and Table S1†). We believe that the ICT band is not observed for the $\mathrm{C}_{16}$ IDT-fDTBT polymer due to the weaker electron-withdrawing ability of the fDTBT moiety, and it is confirmed by TD-DFT as well.

Interestingly, the double band feature, one low-energy lowintensity transition together with one high-energy high-intensity band, was also observed for the isolated fDTBPT unit 3 and



Fig. 7 Simulated UV-Visible absorption (solid line) and its oscillator strength (dashed line) by TD-DFT means at the B3LYP/6-31G(d) level of theory for $\mathrm{C}_{16}$ IDT-fDTBT (black line) and $\mathrm{C}_{16}$ IDT-fDTBPT (red line) trimer systems. 
confirmed by TD-DFT as well (Fig. S3†). This suggested that the fDTBPT unit was ultimately responsible for the final polymer UV-Visible trace.

Photoluminescence (PL) spectra were also acquired for both polymers in solution and solid state (Fig. S4 and S5 $\dagger$ ) by exciting at the main absorption band (i.e. $\pi-\pi^{*}$ transition). $\mathrm{C}_{16}$ IDT-fDTBT was highly emissive in solution and even visible to the naked eye. However, its PL was quenched dramatically in the solid state. On the other hand, emission from the $\mathrm{C}_{16}$ IDT-fDTBPT polymer was very weak in solution and not detectable in the solid state. We could attribute this phenomenon to the presence of low-lying excited states that could promote non-radiative decay pathways as in this particular case, the emission overlaps with the ICT absorption band.

\section{Field-effect transistor performance}

Representative transfer and output characteristics of bottomcontact top-gate field effect transistors are shown in Fig. 8. For both polymers, the transfer characteristics show excellent $I_{\text {on }} / I_{\text {off }}$ ratios of $\sim 10^{6}$ with average hole mobilities of $0.07 \mathrm{~cm}^{2} \mathrm{~V}^{-1} \mathrm{~s}^{-1}$ and $0.03 \mathrm{~cm}^{2} \mathrm{~V}^{-1} \mathrm{~s}^{-1}$ extracted for $\mathrm{C}_{16}$ IDTfDTBT and $\mathrm{C}_{16} \mathrm{IDT}$-fDTBPT, respectively. The polymers show low threshold voltages of $-9 \mathrm{~V}\left(\mathrm{C}_{16}\right.$ IDT-fDTBT $)$ and $-10 \mathrm{~V}$ $\left(\mathrm{C}_{16}\right.$ IDT-fDTBPT $)$, which suggests that FET operation is not limited by charge injection. The linear output characteristics recorded for both polymers, as well as the turn-on at $\sim 0 \mathrm{~V}$
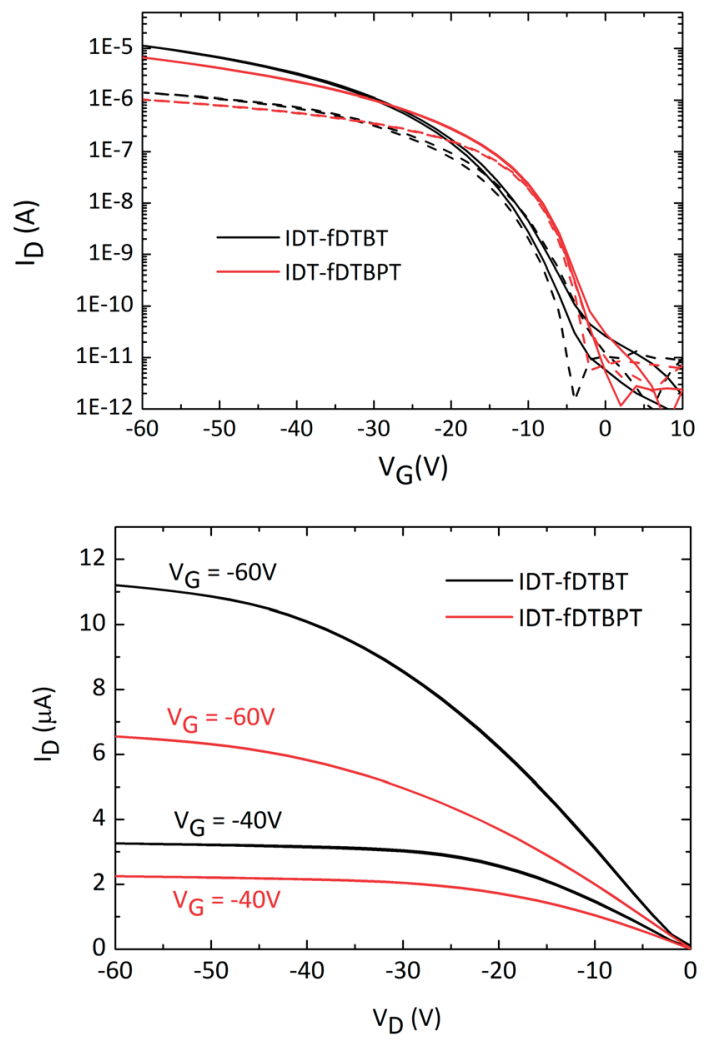

Fig. 8 Transfer (top) and output (bottom) characteristic curves of $\mathrm{C}_{16}$ IDT polymers $(L=20 \mu \mathrm{m}, W=1 \mathrm{~mm})$ measured at $V_{\mathrm{D}}=-5 \mathrm{~V}$ (dashed lines) and $V_{D}=-60 \mathrm{~V}$ (solid lines). furthermore verifies the absence of major injection barriers. The higher mobility obtained for $\mathrm{C}_{16}$ IDT-fDTBT could be attributed to higher defect tolerance for this polymer. In this case, the fDTBT unit has lower conformational energy change by rotation compared to fDTBPT. ${ }^{23}$ It is worth noting that mobilities obtained are 1000-fold higher than the reported polymers containing fDTBT units. ${ }^{24}$

\section{Solar cell properties}

Photovoltaic performance of the polymers was evaluated by preparing bulk-heterojuction solar cells with a conventional device structure containing ITO/PEDOT:PSS/polymer: $\mathrm{PC}_{71} \mathrm{BM} /$ $\mathrm{Ca} / \mathrm{Al}$ and tested under simulated $100 \mathrm{~mW} \mathrm{~cm}^{-2} \mathrm{AM} 1.5 \mathrm{G}$ sun light. The $J-V$ curves are shown in Fig. 9 and the device parameters are summarized in Table 3. The high $V_{\text {OC }}$ obtained for both polymers, exceeding $+0.80 \mathrm{~V}$, is similar for both polymers and is due to the deep HOMO energy level, confirmed by $\mathrm{CV}$ and PESA results. On the other hand, the $J_{\mathrm{SC}}$ obtained for $\mathrm{C}_{16}$ IDT-fDTBT was about twice the value for $\mathrm{C}_{16}$ IDT-fDTBPT. We could partially attribute this to the lower molecular weight for the $\mathrm{C}_{16} \mathrm{IDT}$-fDTBPT polymer as well as a very low-lying LUMO energy level of $-4.05 \mathrm{eV}$, which might limit the efficient charge separation in the polymer: $\mathrm{PC}_{71} \mathrm{BM}$ blend. ${ }^{25,26}$ In fact, the EQE spectra (Fig. 9 - inset) confirmed that the ICT absorption band $(\sim 750 \mathrm{~nm})$ for the $\mathrm{C}_{16}$ IDT-fDTBPT polymer did not contribute to the photocurrent generation, yielding only immobile excitons. Overall, efficiencies of $2.18 \%$ and $1.34 \%$ were obtained for $\mathrm{C}_{16}$ IDT-fDTBT and -fDTBPT, respectively. A major reason for the low PCE values is likely to be due to the presence of long linear, $\mathrm{C}_{16}$, alkyl chains on the IDT unit. In previous studies of IDT polymers, this particular side chain exhibited sub-optimal phase separation and the lowest PCEs. ${ }^{17}$ However, we were limited to $\mathrm{C}_{16}$ alkyl chains to ensure good



Fig. $9 \mathrm{~J}-V$ characteristics of $\mathrm{C}_{16}$ IDT-fDTBT (black line) and $\mathrm{C}_{16}$ IDTfDTBPT (red line) polymer:PC $\mathrm{C}_{71} \mathrm{BM}$ (ratio $1: 3.5$ ) solar cell under $\mathrm{AM}$ 1.5G solar illumination. Inset: external quantum efficiency for both $\mathrm{C}_{16}$ IDT based polymers. 
Table 3 Device merit parameters for $\mathrm{C}_{16}$ IDT based polymers

\begin{tabular}{lllll}
\hline Polymer & $J_{\mathrm{SC}} / \mathrm{mA} \mathrm{cm}^{-2}$ & $\mathrm{PCE} / \%$ & $V_{\mathrm{OC}} / \mathrm{V}$ & $\mathrm{FF}$ \\
\hline fDTBT & 4.95 & 2.18 & 0.82 & 0.54 \\
fDTBPT & 2.82 & 1.34 & 0.81 & 0.58
\end{tabular}

polymer solubility, as co-monomers fDTBT and fDTBPT showed limited solubility.

\section{Conclusions}

We have synthesised and characterised two polymers composed of an electron-rich backbone, comprised of alternating IDT and DT units, with electron-deficient BT and BPT units fused on the DT unit. Both polymers showed a decent molecular weight with narrow polydispersity and good thermal stability. Increasing the electron-withdrawing strength of this BT unit by inserting a pyrazine ring led to a significant difference in the optical properties, turning not only the first electronic transition (HOMO to LUMO) from a $\pi-\pi^{*}$ based to ICT character, but also red-shifting the absorption by $100 \mathrm{~nm}$. Polymers showed promising OFET performance close to $0.1 \mathrm{~cm}^{2} \mathrm{~V}^{-1} \mathrm{~s}^{-1}$ with very small turn on and threshold voltages (less than $-10 \mathrm{~V}$ ). Nevertheless, the strong and sharp absorption of the $\mathrm{C}_{16}$ IDT-fDTBT polymer makes it potentially suitable as a wide band gap polymer for tandem solar cells. Replacement of the IDT linear $\mathrm{C}_{16}$ alkyl chains for branched ethylhexyl $\left(\mathrm{C}_{2} \mathrm{C}_{6}\right)$ should improve the bulk heterojunction morphology.

\section{Acknowledgements}

This work was supported by EU grants 604397 (ArtESun) and 287818 (X10D) as well as Imperial College Doctoral Training Centre (DTC) grant EP/G037515/1. M.N. and M.H. thank gratefully the Technology Strategy Board (TSB) PORSCHED project 101238. We are grateful to Scott E. Watkins (CSIRO Materials Science and Engineering, Victoria, Australia) for his contribution to the polymer energy levels determination by UV-PESA measurements.

\section{Notes and references}

1 A. C. Arias, J. D. MacKenzie, I. McCulloch, J. Rivnay and A. Salleo, Chem. Rev., 2010, 110, 3-24.

2 X. Guo, M. Baumgarten and K. Müllen, Prog. Polym. Sci., 2013, 38, 1832-1908.

3 C. B. Nielsen, M. Turbiez and I. McCulloch, Adv. Mater., 2013, 25, 1859-1880.

4 I. McCulloch, R. S. Ashraf, L. Biniek, H. Bronstein, C. Combe, J. E. Donaghey, D. I. James, C. B. Nielsen, B. C. Schroeder and W. Zhang, Acc. Chem. Res., 2012, 45, 714-722.

5 X. Zhang, H. Bronstein, A. J. Kronemeijer, J. Smith, Y. Kim, R. J. Kline, L. J. Richter, T. D. Anthopoulos, H. Sirringhaus, K. Song, M. Heeney, W. Zhang, I. McCulloch and D. M. DeLongchamp, Nat. Commun., 2013, 4, 3238-1-3238-9.
6 H. N. Tsao, D. M. Cho, I. Park, M. R. Hansen, A. Mavrinskiy, D. Y. Yoon, R. Graf, W. Pisula, H. W. Spiess and K. Müllen, J. Am. Chem. Soc., 2011, 133, 2605-2612.

7 F. A. Arroyave, C. A. Richard and J. R. Reynolds, Org. Lett., 2012, 14, 6138-6141.

8 Y. Xie, T. Fujimoto, S. Dalgleish, Y. Shuku, M. M. Matsushita and K. Awaga, J. Mater. Chem. C, 2013, 1, 3467-3481.

9 M. J. Frisch, et al., Gaussian 09, Revision B.01, Gaussian Inc, Wallingford CT, 2009.

10 M. Hanwell, D. Curtis, D. Lonie, T. Vandermeersch, E. Zurek and G. Hutchison, J. Cheminf., 2012, 4, 17.

11 R. Bauernschmitt and R. Ahlrichs, Chem. Phys. Lett., 1996, 256, 454-464.

12 D. J. Tozer and N. C. Handy, J. Chem. Phys., 1998, 109, 1018010189.

13 N. M. O'Boyle, A. L. Tenderholt and K. M. Langner, J. Comput. Chem., 2008, 29, 839-845.

14 H. Bastian and E. Breitmaier, Chem. Ber., 1985, 118, 12781281.

15 M. Planells and N. Robertson, Eur. J. Org. Chem., 2012, 2012, 4947-4953.

16 F. Würthner, S. Yao, T. Debaerdemaeker and R. Wortmann, J. Am. Chem. Soc., 2002, 124, 9431-9447.

17 H. Bronstein, D. S. Leem, R. Hamilton, P. Woebkenberg, S. King, W. Zhang, R. S. Ashraf, M. Heeney, T. D. Anthopoulos, J. d. Mello and I. McCulloch, Macromolecules, 2011, 44, 6649-6652.

18 R. S. Ashraf, B. C. Schroeder, H. A. Bronstein, Z. Huang, S. Thomas, R. J. Kline, C. J. Brabec, P. Rannou, T. D. Anthopoulos, J. R. Durrant and I. McCulloch, Adv. Mater., 2013, 25, 2029-2034.

19 W. Zhang, J. Smith, S. E. Watkins, R. Gysel, M. McGehee, A. Salleo, J. Kirkpatrick, S. Ashraf, T. Anthopoulos, M. Heeney and I. McCulloch, J. Am. Chem. Soc., 2010, 132, 11437-11439.

20 P. M. Beaujuge, C. M. Amb and J. R. Reynolds, Acc. Chem. Res., 2010, 43, 1396-1407.

21 B. A. Jones, A. Facchetti, M. R. Wasielewski and T. J. Marks, J. Am. Chem. Soc., 2007, 129, 15259-15278.

22 T. M. McCormick, C. R. Bridges, E. I. Carrera, P. M. DiCarmine, G. L. Gibson, J. Hollinger, L. M. Kozycz and D. S. Seferos, Macromolecules, 2013, 46, 3879-3886.

23 H. Sirringhaus, Adv. Mater., 2014, 26, 1319-1335.

24 C.-Y. Mei, L. Liang, F.-G. Zhao, J.-T. Wang, L.-F. Yu, Y.-X. Li and W.-S. Li, Macromolecules, 2013, 46, 7920-7931.

25 S. D. Dimitrov, A. A. Bakulin, C. B. Nielsen, B. C. Schroeder, J. Du, H. Bronstein, I. McCulloch, R. H. Friend and J. R. Durrant, J. Am. Chem. Soc., 2012, 134, 18189-18192.

26 S. D. Dimitrov and J. R. Durrant, Chem. Mater., 2013, 26, 616630.

27 SHELXTL, Bruker AXS, Madison, WI; SHELX-97, G. M. Sheldrick, Acta Crystallogr., Sect. A, 2008, 64, 112122; SHELX-2013, http://shelx.uni-ac.gwdg.de/SHELX/ index.php. 